\title{
The influence of right anterolateral thoracotomy in prepubescent female patients on late breast development and on the incidence of scoliosis
}

\author{
Sabine Bleiziffer, $M D^{\mathrm{a}}$ \\ Christian Schreiber, MD ${ }^{\mathrm{a}}$ \\ Rainer Burgkart, MD \\ Felix Regenfelder, $M D^{b}$ \\ Martin Kostolny, MD \\ Paul Libera, MD ${ }^{\text {a }}$ \\ Klaus Holper, MD \\ Rüdiger Lange, $\mathrm{MD}^{\mathrm{a}}$
}

From the Clinic for Heart Surgery, ${ }^{\text {a }}$ German Heart Center Munich, and Clinic for Orthopaedics, ${ }^{\text {b }}$ Technical University $\mathrm{Mu}-$ nich, Munich, Germany.

Received for publication Sept 3, 2003; revisions requested Nov 11, 2003; revisions received Nov 18, 2003; accepted for publication Dec 2, 2003

Address for reprints: Sabine Bleiziffer, MD, Clinic for Heart Surgery, German Heart Center Munich, Lazarettstr 36, 80636 Munich, Germany (E-mail: bleiziffer@ dhm.mhn.de)

J Thorac Cardiovasc Surg 2004;127: $1474-80$

$0022-5223 / \$ 30.00$

Copyright () 2004 by The American Association for Thoracic Surgery

doi:10.1016/j.jtcvs.2003.11.033
Background: It is assumed that a right anterolateral thoracotomy for correction of simple congenital cardiac defects (ie, atrial septal defect) achieves more favorable cosmetic results than a standard median sternotomy.

Methods: Ninety-five patients, 72 with right anterolateral thoracotomy and 23 with median sternotomy, who had corrective transatrial operations when they were younger than 12 years of age were contacted by questionnaire. The mean follow-up time was 23.1 years. Of these, 61 patients (46 thoracotomy and 15 sternotomy) were investigated clinically. Volume differences of the breasts were measured by 3-dimensional surface scanning. By using photographs of the upper chest, breast symmetry was described by an index. The degree of scoliosis was measured by clinical examination.

Results: According to the questionnaire analysis, $76 \%$ (thoracotomy group) versus $39 \%$ (sternotomy group) thought that the cosmetic result was excellent $(P=.008)$. Breast volume measurement showed a volume difference greater than $20 \%$ (left side larger than right) in 55\% (thoracotomy) versus $0 \%$ (sternotomy). With our index, asymmetry in the lower part of the right breast occurred in 61\% (thoracotomy) versus $0 \%$ (sternotomy; $P<.001$ ). A total of $6.6 \%$ of the patients had scoliosis, without any differences between groups.

Conclusions: Because our long-term follow-up in prepubescent female patients after right anterolateral thoracotomy revealed significantly impaired unilateral breast development, we propose to abandon right anterolateral thoracotomy in this subgroup of patients, although the subjective satisfaction with the cosmetic result was high. To avoid potential damage of future breast tissue, other surgical approaches, such as right posterior thoracotomy, should be considered. According to the orthopedic investigation, the surgical approach does not cause a higher rate of scoliosis.

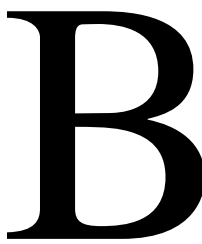

ecause the surgical closure of simple congenital defects, such as atrial septal defect (ASD), partial atrioventricular septal defect (PAVSD), or sinus venosus defect, is considered to be of high benefit with low morbidity and mortality, the cosmetic sequelae of the operations gain relatively more importance. Routine approaches for ASD closure include median sternotomy (MS) and right anterolateral thoracotomy (ALA). ${ }^{1}$ Lately, new minimally invasive approaches, such as ministernotomy, ${ }^{2}$ transxiphoid approach without sternotomy, ${ }^{3}$ and posterolateral thoracotomy, ${ }^{4,5}$ have gained in popularity. 


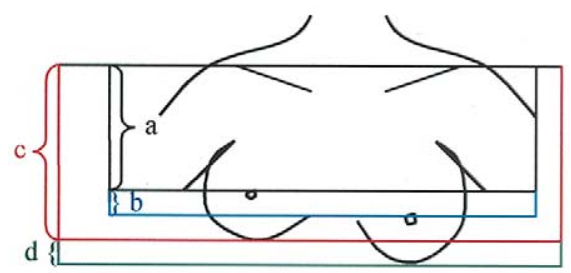

A

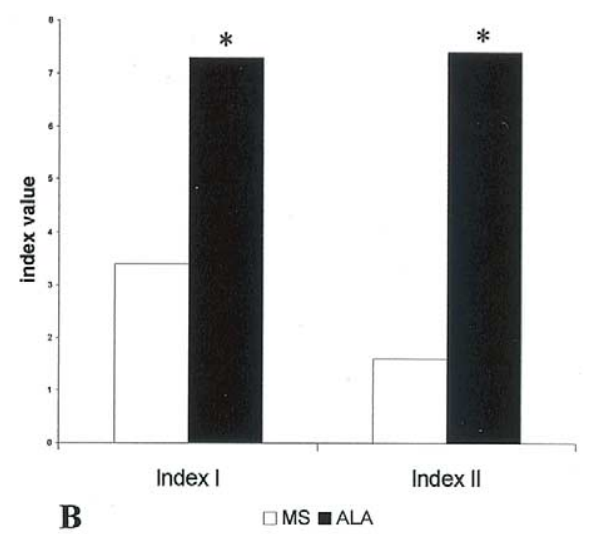

Figure 1. A, Index calculation: index $I=b / a \times 100$; index $I I=$ d/c $\times 100 . B,{ }^{*} P<.001$.

It is assumed that the cosmetic outcome of ALA is superior to that of MS, ${ }^{6}$ especially in adult female patients, ${ }^{7}$ whose breasts are already developed. ${ }^{8}$ However, there are few data about breast development after ALA in prepubescent female patients. ${ }^{9}$ Therefore, we investigated a subgroup of female patients younger than 12 years of age at the time of operation and compared long-term cosmetic results after ALA versus MS. Also, we investigated the hypothesis that because of scarring, an increased rate of left convex thoracic scoliosis after ALA can be found compared with MS and the healthy population.

\section{Patients and Methods}

Between 1974 and 1984, a total of 599 patients had ASD closure at our institution. Of these, 184 patients were prepubescent females younger than 12 years of age. As a first step in our investigation, 95 of these patients ( 72 with ALA and 23 with MS) were contacted with a questionnaire analysis to evaluate subjective cosmetic results. Sixty-nine of these patients had ASD from secundum type, 13 had PAVSD, and 13 had sinus venosus defect. Six patients had additional valvular pulmonary stenosis. Average age and weight at operation were $6.0 \pm 3.0$ years and $20.2 \pm 7.5 \mathrm{~kg}$, respectively (range, $5-47 \mathrm{~kg}$; MS, $14.9 \pm 6.1 \mathrm{~kg}$; ALA, $21.6 \pm 7.2 \mathrm{~kg}$ ). The mean follow-up time was 23.1 years (range, 17-28 years; median, 23 years). In our questionnaire, the length and aspect of the scar, psychological effect (ie, effect on self-confidence), and subjective assessment of the symmetry and volume difference of the breasts were evaluated.

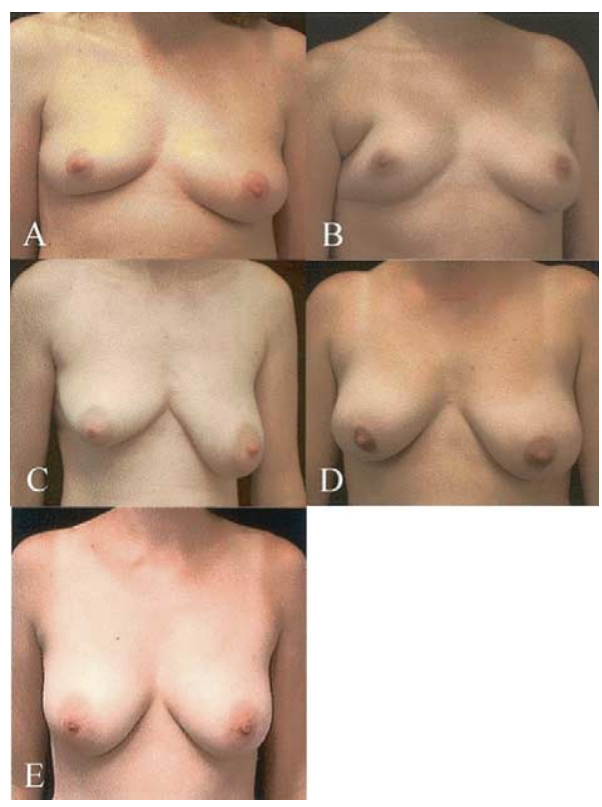

Figure 2. A-D, Unfavorable outcome after ALA. E, Good cosmetic outcome after ALA in a woman who was operated on at the age of 5 years.

As a second step, 61 of these patients (46 with ALA and 15 with MS) were recruited for examination at our institution. The mean age of the patients was $29.6 \pm 4.6$ years, mean weight was $62.1 \pm 9.7 \mathrm{~kg}$, and mean height was $168 \pm 7.5 \mathrm{~cm}$. Electrocardiogram and transthoracic echocardiography were performed to assess the completeness of correction. Orthopedic specialists investigated the degree of scoliosis by clinical examination and 3-dimensional spine scanning (Formetric II; Diers, Wiesbaden, Germany). ${ }^{10}$ The patients were tested for thoracic or lumbar rotation by using a scoliometer - a specially designed inclinometer (Orthopedic Systems, Union City, Calif) - in the Adams forwardbending test position after the leg length was evened out. The scoliometer was placed on the back at the apex of the asymmetry, perpendicular to the long axis of the body. According to Bunnell, ${ }^{11}$ scoliosis was clinically defined as a rotation $7^{\circ}$ or more and a postural scoliosis between $3^{\circ}$ and $6^{\circ}$. Additionally, we used the Formetric II apparatus for surface scanning of the breasts to measure volume differences. For these purposes, the data were converted into suitable data format (rek2raw) files and edited with specially programmed software in addition to the graphics program Amira 3.0 Dev (TGS, Metz, France).

\section{Index Method}

By using photographs of the upper chest, indices were calculated to describe differences in the size and shape of the breasts. Index I describes asymmetry at the level of the nipples, and index II describes asymmetry at the level of the lower part of the breasts. An index of 0 indicates symmetrical breast development. The higher the index, the more likely that asymmetry of the breasts occurred (Figure 1). Informed consent was obtained from all patients included in the study. 
TABLE 1. Echocardiographic findings

\begin{tabular}{ll}
\hline Diagnosis & \multicolumn{1}{c}{$\%(\mathbf{n}=\mathbf{6 1})$} \\
\hline Residual ASD & $0 \%$ \\
End-diastolic right ventricle & $48 \%$ \\
$\quad$ enlargement $>20 \mathrm{~mm}$ & \\
Mitral regurgitation & Mild 15\% \\
Tricuspid regurgitation & Moderate 3\% \\
& Mild 36\% \\
& Moderate $11 \%$ \\
\hline
\end{tabular}

$A S D$, Atrial septal defect.

\section{Operative Technique}

Standard MS was performed for PAVSD or in patients weighing less than $16 \mathrm{~kg}(14.9 \pm 6.1 \mathrm{~kg})$. ALA thoracotomy followed positioning of the patient in a $45^{\circ}$ anterior oblique position. Over the years, only 5 surgeons operated on this cohort of patients. Skin incision was performed meticulously 3 to $4 \mathrm{~cm}$ below the nipple, always in the same fashion. Subcutaneous tissue was dissected right down to the fascia up to the fourth rib. Parts of the pectoral muscle were cut in a horizontal direction. The thorax was opened preferentially in the bed of the fourth rib (in few cases, the third or fifth rib). An adequate exposure of the heart was achieved after opening of the pericardium and placement of numerous stay sutures. Arterial cannulation was performed by right femoral access. Usually, the right atrium was opened under normothermia, with snaring of the superior and inferior vena cava and electrically induced fibrillation of the heart. After bicaval cannulation and establishment of cardiopulmonary bypass, aortic crossclamping, myocardial protection under mild hypothermia, and antegrade crystalloid cardioplegia followed only in patients with PAVSD or sinus venosus defect. Two sump suckers, of which 1 was placed in the coronary sinus, allowed clear exposure of the right atrial cavity. The interatrial defect was closed subsequently either with direct suture or patch material. After deairing, the heart was defibrillated.

\section{Statistical Analysis}

Data are presented as mean \pm SD and as simple percentages. Questionnaire analysis was performed with the $\chi^{2}$ test. Indices and volumetry data were analyzed with the Mann-Whitney test.

\section{Results}

\section{Hemodynamic and General Status}

Electrocardiogram was normal in 57 patients; 3 patients had an implanted DDD pacemaker for atrioventricular block III or supraventricular tachyarrhythmias. Two of them had already shown arrhythmias before the operation, and atrioventricular block III developed in 1 patient 5 years after the operation. One patient had asymptomatic atrioventricular block I.

Echocardiography showed no residual ASD in any patient. Tricuspid regurgitation was found in 29 patients by visual assessment, ${ }^{12}$ and end-diastolic enlargement of the right ventricle was greater than $20 \mathrm{~mm}$ in 29 patients. Mild or moderate mitral reflux was ascertained in 11 patients. $^{12}$
All patients had normal left ventricular function. Echocardiographic findings are summarized in Table 1.

One patient with moderate mitral reflux complained of dyspnea on exertion, and 2 patients had had supraventricular tachyarrhythmias several years previously. One patient had overcome myocarditis in 1993. Except for the patient with mitral reflux, all patients were free from cardiac symptoms at the time of investigation. Two patients were taking metoprolol for increased blood pressure; 1 patient with an implanted pacemaker for supraventricular tachyarrhythmias was receiving mexiletine and sotalol.

Seventeen women in the ALA group already had children. Four of them reported that they had produced less milk on the right side.

\section{Orthopedic Findings}

The orthopedic examination revealed clinical scoliosis in 4 patients $(6.6 \%)$, postural scoliosis in $42.6 \%$, and normal posture in $31(50.8 \%)$. In the group with scoliosis, 2 patients had had MS and 2 had had ALA. The lumbar rotation in this group was always to the left side $(\mathrm{n}=4)$. The mean value was $10.25^{\circ}(\mathrm{SD} \pm 5.3)$. The mean thoracic rotation, always to the right side, was $7^{\circ}$ ( $\mathrm{SD} \pm 6.5$ ).

Two of the patients had severe scoliosis. One had a left convex lumbar scoliosis of $19^{\circ}$ and a thoracic rotation to the right side of $9^{\circ}$ (ALA). The other patient had a right convex thoracic rotation of $18^{\circ}$ and a left convex lumbar rotation of $7^{\circ}$ (MS). Seven patients (11.7\% of all patients) had a left convex thoracic spine as a postural scoliosis, with a mean rotation of $3.4^{\circ}(\mathrm{SD} \pm 1.3$; Table 2$)$.

\section{Breast Development}

According to the questionnaire analysis, the psychological effect of the operation was comparable in both groups when patients were asked about awkwardness with a partner or when naked. Still, impairment of self-confidence was less in the ALA group $(P=.036)$.

The length of the scar was comparable: $19.8 \mathrm{~cm}$ in the ALA group versus $20.8 \mathrm{~cm}$ in the MS group $(P=.557, \mathrm{NS})$. A total of $64 \%$ (ALA group) versus 22\% (MS group) thought that the right breast was smaller $(P=.015)$.

A total of $31 \%$ (ALA group) versus $13 \%$ (MS group) reported numbness $(P=.313$, NS), and $7 \%$ versus $4 \%$ reported pain in the region of the scar on exertion or during a change of weather $(P=.96, \mathrm{NS})$. A total of $76 \%$ (ALA) versus $39 \%$ (MS) considered the cosmetic result excellent $(P=.008)$. The questionnaire results are summarized in Table 3.

The scar itself was a thin and pale line in most cases. Two patients had keloids (1 ALA and 1 MS). Six patients had a broad scar (2 ALA and 4 MS). In 8 patients of the ALA group, the scar went through the lower part of the breast tissue. Examples of the cosmetic outcome after ALA are shown in Figure 2. 
TABLE 2. Orthopedic findings

\begin{tabular}{|c|c|c|}
\hline Variable & ALA & MS \\
\hline Normal posture ( $\mathrm{n}=31 ; 50.8 \%$ ) & $\mathrm{n}=26$ & $\mathrm{n}=5$ \\
\hline $\begin{array}{l}\text { Postural scoliosis ( } n=26 \text {; } \\
\quad 42.6 \% \text { ) }\end{array}$ & $\mathrm{n}=18$ & $\mathrm{n}=8$ \\
\hline Mean left thoracic rotation & $3.1^{\circ}(S D=1.2) n=7$ & $5^{\circ}(n=1)$ \\
\hline Mean right thoracic rotation & $3.7^{\circ}(S D=0.9) \mathrm{n}=10$ & $4(S D=1.2) n=7$ \\
\hline No thoracic rotation & $n=1$ & $\mathrm{n}=0$ \\
\hline Mean left lumbar rotation & $2.7^{\circ}(S D=1.2) \mathrm{n}=12$ & $1.8^{\circ}(\mathrm{SD}=0.84) \mathrm{n}=5$ \\
\hline Mean right lumbar rotation & $2.8^{\circ}(S D=1.3) n=5$ & $2^{\circ} \mathrm{n}=1$ \\
\hline No lumbar rotation & $\mathrm{n}=1$ & $\mathrm{n}=2$ \\
\hline Scoliosis $(n=4 ; 6.6 \%)$ & $\mathrm{n}=2$ & $\mathrm{n}=2$ \\
\hline Mean left thoracic rotation & $\mathrm{n}=0$ & $\mathrm{n}=0$ \\
\hline Mean right thoracic rotation & $6^{\circ}(\mathrm{SD}=4.2) \mathrm{n}=2$ & $18^{\circ} \mathrm{n}=1$ \\
\hline No thoracic rotation & $\mathrm{n}=0$ & $\mathrm{n}=1$ \\
\hline Mean left lumbar rotation & $13^{\circ}(S D=8.5) n=2$ & $7.5^{\circ}(\mathrm{SD}=0.7) \mathrm{n}=2$ \\
\hline Mean right lumbar rotation & $\mathrm{n}=0$ & $\mathrm{n}=0$ \\
\hline No lumbar rotation & $\mathrm{n}=0$ & $\mathrm{n}=0$ \\
\hline
\end{tabular}

$M S$, Median sternotomy; $A L A$, right anteriolateral thoracotomy.

Three-dimensional surface scanning showed a mean volume difference of $27 \% \pm 16.4 \%$ (ALA) compared with $8 \%$ $\pm 5.6 \%$ (MS) in those cases in which the right side was the smaller one $(P<.001)$. All but 3 women of the ALA group had a smaller right breast. A volume difference of greater than $20 \%$ occurred in $55 \%$ of the ALA group. Figure 3 shows the distribution of percentage volume difference for individual breast pairs in the 2 groups.

The evaluation of standardized photographs revealed a mean index I and II of $3.4 \pm 2.4$ and $1.6 \pm 1.4$, respectively, in the MS group (Figure 1). In the ALA group, the mean index I was increased to $7.3 \pm 5.5(P<.001)$, and index II was $7.4 \pm 4.9(P<.001)$. Twenty-eight percent of the women of the ALA group had an index I higher than 3 SD above the mean value of the MS group, and $61 \%$ had an index II higher than $3 \mathrm{SD}$ above the mean value of the MS group. We found no correlation between the degree of asymmetry of the breasts and the age of the patients at the time of operation.

\section{Discussion}

The first successful ASD closure was performed via right anterolateral thoracotomy by F. J. Lewis in $1952 .{ }^{13}$ Over the years, with increasing experience, the operative mortality decreased dramatically. ${ }^{3,14}$ Today, percutaneous transcatheter closure of ASD is becoming an accepted technique as an alternative to surgery. ${ }^{15}$ However, limitations for the interventional closure are defect size, insufficient rim, and complex anatomy.

After its introduction in 1957 by O. C. Julian, ${ }^{16}$ the MS was the universal method of exposure for most cardiac procedures. However, especially in patients with simple congenital cardiac defects, a prominent midline scar remains an unsightly and lifelong reminder of an otherwise low-risk and successful procedure.
TABLE 3. Questionnaire analysis

\begin{tabular}{lcc}
\hline Variable & $\begin{array}{c}\text { ALA } \\
\text { (n = 72) }\end{array}$ & $\begin{array}{c}\text { MS } \\
\text { (n = 23) }\end{array}$ \\
\hline $\begin{array}{l}\text { No impairment of self-confidence } \\
\quad \text { through scarring }\end{array}$ & $94 \%$ & $73 \%$ \\
Absence of awkwardness & & \\
$\quad$ When naked & $90 \%$ & $83 \%$ \\
$\quad$ With a partner & $90 \%$ & $96 \%$ \\
Smaller right breast & $64 \%$ & $22 \%$ \\
Equal breast size & $29 \%$ & $48 \%$ \\
Scar not visible when wearing bra & $72 \%$ & $0 \%$ \\
Numbness & $31 \%$ & $13 \%$ \\
Pain & $7 \%$ & $4 \%$ \\
Subjective satisfaction with the & & \\
$\quad$ cosmetic result & & \\
$\quad$ Excellent & $76 \%$ & $39 \%$ \\
Good & $15 \%$ & $52 \%$ \\
Not satisfying & $8 \%$ & $9 \%$ \\
\hline
\end{tabular}

$M S$, Median sternotomy; $A L A$, right anteriolateral thoracotomy.

Alternative approaches with the aim of a nearly invisible scar remained a surgical goal. A bilateral submammary skin incision with transverse sternotomy was 1 example. ${ }^{17} \mathrm{How}-$ ever, frequent complications, including breast maldevelopment, reduced areola sensitivity, and hematomas, restricted the use of this approach.

Since the early seventies, ALA has been used as a safe alternative for MS. Review of the literature revealed that most authors favor the cosmetic advantage of ALA,,${ }^{6,718-21}$ because the scar can be hidden easily when the patient is adequately dressed - the scar disappears under the breast. ${ }^{1}$ Patients' acceptance of this surgical approach is very high. In our study, $76 \%$ stated that the cosmetic result was "excellent." 


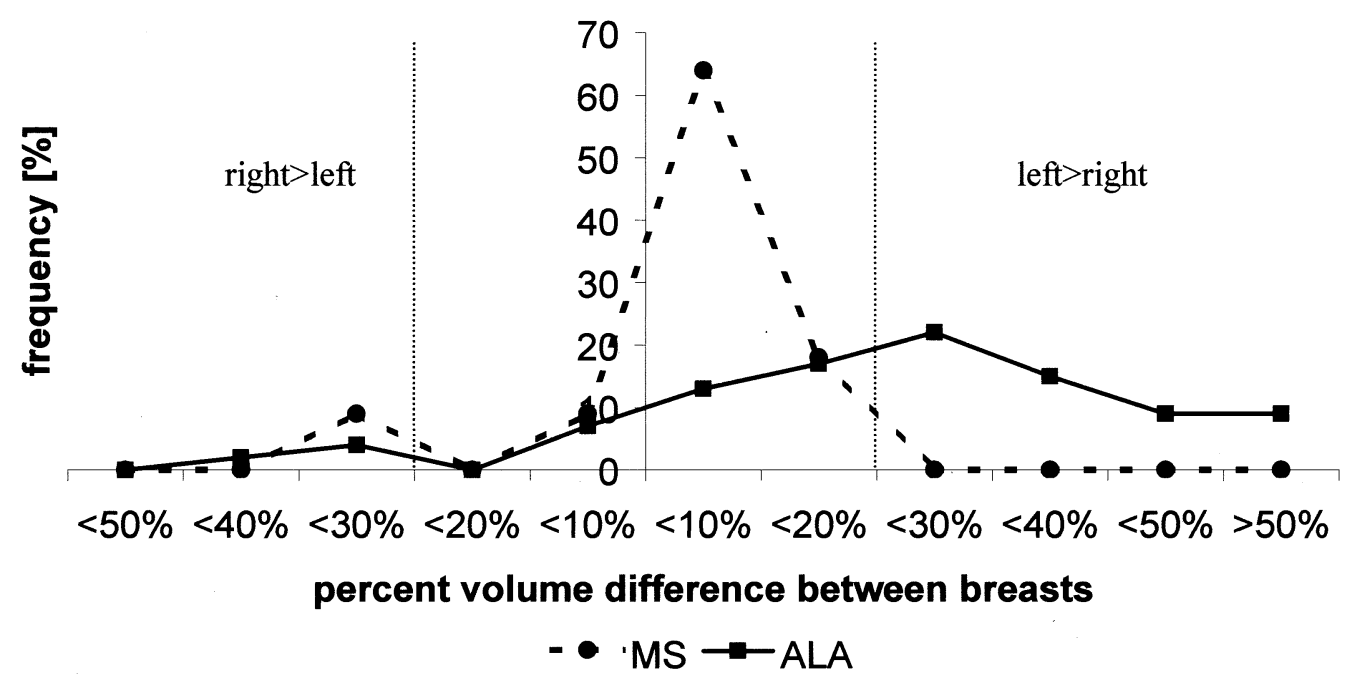

Figure 3. Results of 3-dimensional surface scanning. The percentage volume difference of individual breast pairs (compared with the smaller side) is shown for the cases in which the left breast was the smaller one (left) and when the right breast was the smaller one (right). After MS, $92 \%$ of the patients showed a breast volume difference of less than $\mathbf{2 0} \%$. In the ALA group, $55 \%$ had a volume difference greater than $\mathbf{2 0} \%$ (left side greater than right; $\boldsymbol{P}$ $<.001$ ).

Beside this cosmetic consideration, which will be discussed later in more detail, part of our study aimed to evaluate whether this right lateral scar increases the risk of left convex thoracic scoliosis. The prevalence of scoliosis in the healthy population varies from $1 \%$ to $21 \%$ because of the different criteria used for the detection and diagnosis of scoliosis. ${ }^{22}$ However, in contrast to our hypothesis of the potential shortening effect of the scar tissue, we found no higher incidence of left convex deformities (Table 2). We found that the surgical approach does not cause a higher rate or a preferential direction of scoliosis in the studied patients compared with reference data.

Another issue is potential phrenic nerve damage (PND) after ALA. We and Dabritz and associates ${ }^{1}$ (87 patients) found no evidence of PND, whereas Helps and colleagues ${ }^{23}$ observed PND in an unusually high rate of $31 \%$ (5/16 patients). The exact operative techniques that are known to affect nerve function may be multifactorial (direct injury, electrocautery used near a nerve, extensive thymus dissection, placement of pericardial stay sutures and traction, internal jugular vein cannulation, and topical cooling). However, in our opinion, the anterolateral approach can be used safely by appreciating the course of the nerve, pulling adequately on the pericardial traction sutures, and avoiding topical cooling.

To avoid breast asymmetry after ALA, Dietl and colleagues ${ }^{24}$ proposed a subpectoral rather than transpectoral approach. The mean age of their patients was 21.5 years (range, 8-38 years). Their patient selection, however, obscured breast maldevelopment in the prepubescent girls, because the follow-up time reached only 5 years. We believe that the major drawback of most publications ${ }^{6,7,18-21}$ is that the investigators did not differentiate between children before breast development and female patients with defined submammary grooves in an adequately large long-term cohort. Recently, Tiete and associates ${ }^{25}$ published their results after ALA in prepubescent girls (age, $5.8 \pm 4.1$ years), but again the follow-up time was only $4.8 \pm 4.6$ months, which must be considered too short to detect breast maldevelopment.

Only Cherup and colleagues ${ }^{9}$ measured volume differences of the breast and pectoral muscle in 22 men and women who had undergone right or left anterolateral or left posterolateral thoracotomy as children. Follow-up time was approximately 20 years. They found a volume difference greater than $20 \%$ in $60 \%$ of the patients by a method using plaster molds. Unfortunately, this publication lacks a description of the number of female patients and age distribution. Furthermore, 3 different surgical approaches were investigated in a small cohort of only 22 patients without splitting up the results.

Our study is unique in that it measured breast volume differences after 1 defined surgical approach (ALA). Our proposed index method and the use of the Formetric II instrument for objective measurement of breast volume differences have not previously been described in the literature.

What may be the reasons for later breast maldevelopment after ALA? Infant cadaver dissections showed distribution of breast bud tissue (mamma ductules and glands) in 
a periphery of at least $1.5 \mathrm{~cm}$ around the nipple-areola complex. ${ }^{9}$ These findings support the assumption that a dissection in this area may damage future breast tissue with the consequence of incomplete breast development.

It is well known that breast asymmetry also occurs in the healthy population. Loughry and colleagues ${ }^{26}$ measured the breast volumes of 598 women by stereophotogrammetry. They found a volume difference of $20 \%$ or less in $70 \%$ of the women. In the cases of volume difference, the proportion of a smaller right breast tended to be slightly higher, at $4 \%$ (NS). This indicates that a volume difference of up to $20 \%$ might be normal and that the right breast is more often the smaller one. In contrast, in our study $93.5 \%$ of the ALA group had a smaller right breast, with an average volume difference of $27 \%$, compared with $8 \%$ in the MS group. A volume difference of $20 \%$ or less (compared with the smaller side) occurred in only 38\% (ALA) versus $92 \%$ (MS) or $70 \%$ (healthy population ${ }^{26}$ ). Our calculated index II, which describes the asymmetry of the lower part of the breasts, was more than $3 \mathrm{SD}$ above normal distribution in $61 \%$, indicating a maldevelopment especially in this region after ALA.

Our findings question the use of ALA in prepubescent female patients. We found the right breast development to be significantly impaired. However, questionnaire analysis showed that most patients preferred a lateral scarring. This underlines the patient's wish for a cosmetically favorable surgical approach. As proposed by Grinda and associates ${ }^{8}$ and Bauer and associates, ${ }^{27}$ ALA should therefore be chosen only in female patients whose breasts are already developed and whose submammary grooves are well defined.

A cosmetically more favorable surgical approach for prepubescent girls might be a more posterior right lateral thoracotomy (PLA). It was first described by Sousa $\mathrm{Uva}^{28}$ in 1995 and is now successfully performed by several institutions. Equally, Liu and colleagues ${ }^{29}$ describe a lateral thoracotomy between the anterior and posterior axillary line for the correction of cardiac defects in children to avoid breast maldevelopment. The growing experience with PLA supports its being a safe and low-risk procedure. Damaging of future breast tissue through this incision is not likely.

Still, there are some limitations for PLA. For example, the presence of a left superior vena cava draining into the coronary sinus is a contraindication. ${ }^{5}$ Also, patients who weigh less than $16 \mathrm{~kg}$ should not undergo lateral thoracotomy because of poor exposure due to small size. In these cases, we favor a lower vertical skin incision for a subxiphoid approach, with or without partial sternotomy. Levinson and Fonger $^{3}$ were the first to describe an ASD closure without sternotomy in 1997. Recently, Hagl and colleagues ${ }^{30}$ introduced their results after a subxiphoid approach without sternotomy, with partial sternotomy, or limited skin incision with full sternotomy in children. Safety, bypass time, and crossclamp time, as well as the duration of hospital stay, were comparable to those of the standard procedure with full skin incision and full sternotomy. Other authors also describe the lower skin incision with or without partial sternotomy as a safe procedure with good exposure, especially for transatrial corrections in children. ${ }^{2}$ Cosmetic results are still superior to a total sternotomy because the remaining scar does not cross the upper part of the anterior thorax, the so-called décolleté, which was the most bothersome item for female patients who underwent MS, as shown in our study.

In conclusion, for cosmetic advance, surgical approaches other than ALA, such as right posterolateral thoracotomy, should be considered as a first choice for younger girls. However, in adult women, right anterolateral thoracotomy still achieves the most favorable cosmesis.

\section{References}

1. Dabritz S, Sachweh J, Walter M, Messmer BJ. Closure of atrial septal defects via limited right anterolateral thoracotomy as a minimal invasive approach in female patients. Eur J Cardiothorac Surg. 1999;15: 18-23.

2. Nicholson IA, Bichell DP, Bacha EA, del Nido PJ. Minimal sternotomy approach for congenital heart operations. Ann Thorac Surg. 2001;71:469-72.

3. Levinson ML, Fonger J. Minimally invasive atrial septal defect closure using the subxyphoid approach. Heart Surg Forum. 1998;1:49-53.

4. Metras D, Kreitmann B. Correction of cardiac defects through a right thoracotomy in children. J Thorac Cardiovasc Surg. 1999;117:1040-2.

5. Houyel L, Petit J, Planche C, Sousa-Uva M, Roussin R, Belli E, et al. Right postero-lateral thoracotomy for open heart surgery in infants and children. Indications and results. Arch Mal Coeur Vaiss. 1999;92: 641-6.

6. Rosengart TK, Stark JF. Repair of atrial septal defect through a right thoracotomy. Ann Thorac Surg. 1993;55:1138-40.

7. Massetti M, Babatasi G, Rossi A, Neri E, Bhoyroo S, Zitouni S, et al. Operation for atrial septal defect through a right anterolateral thoracotomy: current outcome. Ann Thorac Surg. 1996;62:1100-3.

8. Grinda JM, Folliguet TA, Dervanian P, Mace L, Legault B, Neveux JY. Right anterolateral thoracotomy for repair of atrial septal defect. Ann Thorac Surg. 1996;62:175-8.

9. Cherup LL, Siewers RD, Futrell JW. Breast and pectoral muscle maldevelopment after anterolateral and posterolateral thoracotomies in children. Ann Thorac Surg. 1986;41:492-7.

10. Liljenqvist U, Halm H, Hierholzer E, Drerup B, Weiland M. 3-Dimensional surface measurement of spinal deformities with video rasterstereography. Z Orthop Ihre Grenzgeb. 1998;136:57-64.

11. Bunnell WP. Outcome of spinal screening. Spine. 1993;18:1572-80.

12. Rivera JM, Vandervoort PM, Morris E, Weyman AE, Thomas JD. Visual assessment of valvular regurgitation: comparison with quantitative Doppler measurements. J Am Soc Echocardiogr. 1994;7:480-7.

13. Lewis FJ, Taufic M. Closure of atrial septal defects with the aid of hypothermia: experimental accomplishments and report of one successful case. Surgery. 1953;33:52-9.

14. Lange R, Schreiber C, Gunther T, Wottke M, Haas F, Meisner F, et al. Results of biventricular repair of congenital cardiac malformations: definitive corrective surgery? Eur J Cardiothorac Surg. 2001;20:120713.

15. Latson LA. Per-catheter ASD closure. Pediatr Cardiol. 1998;19:8693.

16. Julian OC, Lopez-Belio M, Dye WS, Javid H, Grove WJ. The median sternal incision in intracardiac surgery with extracorporeal circulation: a general evaluation of its use in heart surgery. Surgery. 1957;42:75361 . 
17. Laks H, Hammond GL. A cosmetically acceptable incision for the median sternotomy. J Thorac Cardiovasc Surg. 1980;79:146-9.

18. Cremer JT, Boning A, Anssar MB, Kim PY, Pethig K, Harringer W, et al. Different approaches for minimally invasive closure of atrial septal defects. Ann Thorac Surg. 1999;67:1648-52.

19. Giamberti A, Mazzera E, Di Chiara L, Ferretti E, Pasquini L, Di Donato RM. Right submammary minithoracotomy for repair of congenital heart defects. Eur J Cardiothorac Surg. 2000;18:678-82.

20. Lancaster LL, Mavroudis C, Rees AH, Slater AD, Ganzel BL, Gray LA Jr. Surgical approach to atrial septal defect in the female. Right thoracotomy versus sternotomy. Am Surg. 1990;56:218-21.

21. Abdel-Rahman U, Wimmer-Greinecker G, Matheis G, Klesius A, Seitz U, Hofstetter R, et al. Correction of simple congenital heart defects in infants and children through a minithoracotomy. Ann Thorac Surg. 2001;72:1645-9.

22. Karachalios T, Sofianos J, Roidis N, Sapkas G, Korres D, Nikolopoulos K. Ten-year follow-up evaluation of a school screening program for scoliosis. Is the forward-bending test an accurate diagnostic criterion for the screening of scoliosis? Spine. 1999;24:2318-24.

23. Helps BA, Ross-Russell RI, Dicks-Mireaux C, Elliott MJ. Phrenic nerve damage via right thoracotomy in older children with secundum ASD. Ann Thorac Surg. 1993;56:328-30.

24. Dietl CA, Torres AR, Favaloro RG. Right submammarian thoracot- omy in female patients with atrial septal defects and anomalous pulmonary venous connections. Comparison between the transpectoral and subpectoral approaches. J Thorac Cardiovasc Surg. 1992;104: 723-7.

25. Tiete AR, Sachweh JS, Kozlik-Felmann R, Netz H, Reichart B, Daebritz SH. Minimally invasive surgery for congenital heart defects in paediatric patients. Thorac Cardiovasc Surg. 2002;50:271-5.

26. Loughry CW, Sheffer DB, Price TE, Einsporn RL, Bartfei RG, Morek WM, et al. Breast volume measurement of 598 women using biostereometric analysis. Ann Plast Surg. 1989;22:380-5.

27. Bauer M, Alexi-Meskishvilli V, Nakic Z, Redzepagic S, Bauer U, Weng Y, et al. The correction of congenital heart defects with less invasive approaches. Thorac Cardiovasc Surg. 2000;48:67-71.

28. Sousa Uva M, Roussin R, Petit J, Lacour-Gayet F, Serraf A, Planche C. Right posterolateral thoracotomy in the treatment of simple and isolated lesions of the heart. Presse Med. 1995;24:402-4.

29. Liu YL, Zhang HJ, Sun HS, Li SJ, Yan J, Su JW, et al. Repair of cardiac defects through a shorter right lateral thoracotomy in children. Ann Thorac Surg. 2000;70:738-41.

30. Hagl C, Stock U, Haverich A, Steinhoff G. Evaluation of different minimally invasive techniques in pediatric cardiac surgery: is a full sternotomy always a necessity? Chest. 2001;119:622-7. 